Check for updates

Cite this: J. Mater. Chem. A, 2018, 6, 19520

Received 3rd April 2018

Accepted 14th August 2018

DOI: $10.1039 / \mathrm{c} 8 \mathrm{ta0} 03031 \mathrm{f}$

rsc.li/materials-a

\title{
Effects of fluorination and thermal annealing on charge recombination processes in polymer bulk-heterojunction solar cells $\uparrow$
}

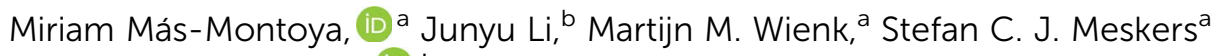 \\ and René A. J. Janssen (iD *ac
}

\begin{abstract}
We investigate the effect of fluorination on the photovoltaic properties of an alternating conjugated polymer composed of 4,8-di-2-thienylbenzo[1,2-b:4,5- $\left.b^{\prime}\right]$ dithiophene (BDT) and 4,7-bis([2,2'bithiophen]-5-yl)-benzo-2-1-3-thiadiazole (4TBT) units in bulk-heterojunction solar cells. The unsubstituted and fluorinated polymers afford very similar open-circuit voltages and fill factor values, but the fluorinated polymer performed better due to enhanced aggregation which provides a higher photocurrent. The photovoltaic performance of both materials improved upon thermal annealing at $150-200{ }^{\circ} \mathrm{C}$ as a result of a significantly increased fill factor and open-circuit voltage, counteracted by a slight loss in photocurrent. Detailed studies of the morphology, light intensity dependence, external quantum efficiency and electroluminescence allowed the exploration of the effects of fluorination and thermal annealing on the charge recombination and the nature of the donor-acceptor interfacial charge transfer states in these films.
\end{abstract}

\section{Introduction}

Intense and fruitful research efforts made during the last few years in terms of materials design and device engineering have positioned organic photovoltaics as a future competitor for traditional inorganic semiconductor based photovoltaic technologies. ${ }^{1}$ To become a commercially viable technology, organic solar cells still have to overcome several limitations, ${ }^{2}$ especially concerning their comparatively higher voltage losses. Reducing the photon energy losses of the optical gap $\left(E_{\mathrm{g}}\right)$ relative to the open-circuit voltage $\left(V_{\mathrm{OC}}\right)$ is one of key aspects to enhance the power conversion efficiency (PCE) of organic photovoltaics., The photon energy loss ranges between 0.5 and $0.7 \mathrm{eV}$ up to $1 \mathrm{eV}$, even for the most efficient systems to date. ${ }^{5-7}$ These voltage losses have, amongst others, been associated with the binding energy of the charge-transfer (CT) state ${ }^{8}$ energetic interfacial disorder, ${ }^{9}$ the dielectric constant of the donor-acceptor blends, ${ }^{\mathbf{1 0}}$ and radiative and non-radiative recombination losses. ${ }^{11,12}$ Evidently, the mechanisms involved in the charge generation and recombination are not only related to the

\footnotetext{
${ }^{a}$ Molecular Materials and Nanosystems, Institute for Complex Molecular Systems, Eindhoven University of Technology, P.O. Box 513, 5600 MB Eindhoven, The Netherlands

${ }^{b}$ DSM DMSC R\&D Solutions, P.O. Box 18, 6160 MD Geleen, The Netherlands ${ }^{c}$ Dutch Institute for Fundamental Energy Research, De Zaale 20, 5612 AJ Eindhoven, The Netherlands.E-mail: r.a.j.janssen@tue.nl

† Electronic supplementary information (ESI) available. See DOI: 10.1039/c8ta03031f
}

inherent properties of the donor and acceptor materials, but also to the interactions between these two components and, hence, post-deposition treatments intended to modify these interactions in thin films ${ }^{\mathbf{1 3 , 1 4}}$ may affect the nature of the intermolecular CT state..$^{15,16}$

While numerous efficient molecular and polymeric donor materials have been described, ${ }^{17-19}$ fluorine substitution has recently become a thriving strategy to further improve the PCE. ${ }^{20-23}$ The benefits of fluorine have been attributed to the planarization of the polymer chains promoted by establishing weak non-covalent $\mathrm{F} \cdots \mathrm{S}, \mathrm{F} \cdots \mathrm{H}$, and $\mathrm{F} \cdots \pi$ inter- and intramolecular interactions, to a lowering of the frontier orbital energy levels by fluorine's inductive electron-withdrawing character, to the improved miscibility with fullerene acceptors, and to enhanced charge transport properties. These factors can influence the $V_{\mathrm{OC}}$, short-circuit current $\left(J_{\mathrm{SC}}\right)$ and fill factor (FF), and in consequence, the device PCE. ${ }^{24-27}$

To investigate the effect of fluorination, we designed two new donor-acceptor copolymers combining benzo[1,2- $\left.b: 4,5-b^{\prime}\right]$ dithiophene $(\mathrm{BDT})^{28}$ with unsubstituted and difluoro-substituted 4,7-bis([2,2'-bithiophen]-5-yl)-benzo-2-1-3-thiadiazole (4TBT and 4TffBT) units. $^{29}$ The two polymers, PBDT4TBT and PBDT4TffBT, are shown in Scheme 1. Linear hexyl and decyl side chains were introduced on the thiophene rings to improve processability. ${ }^{30} \mathrm{We}$ find that fluorination reduces the energy of the highest occupied molecular orbital (HOMO), but that the two polymers afford a very similar $V_{\mathrm{OC}}$ in bulk-heterojunction (BHJ) solar cells. The performance of the $\mathrm{BHJ}$ devices was significantly improved upon thermal annealing at $150-200{ }^{\circ} \mathrm{C}$, by an increased $V_{\mathrm{OC}}$ and $\mathrm{FF}$. The 


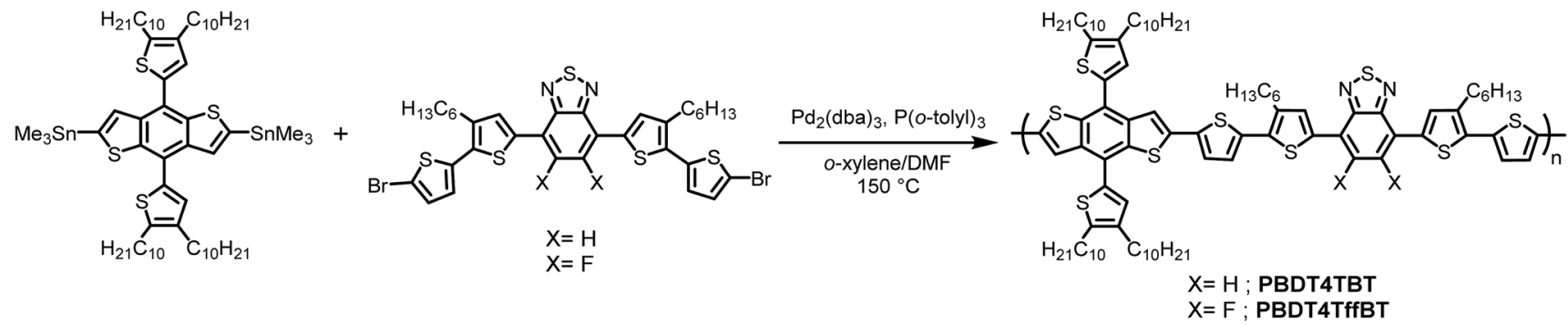

Scheme 1 Synthesis of polymers PBDT4TBT and PBDT4TffBT.

possible reasons were investigated by studying charge recombination and the nature of the charge transfer states by means of light intensity dependent experiments, high sensitivity external quantum efficiency and electroluminescence measurements.

\section{Results and discussion}

\section{Synthesis}

PBDT4TBT and PBDT4TfB were synthesized via a Stille coupling polymerization reaction involving the distannylated BDT and the corresponding dibrominated 4TBT and 4TffBT comonomers (Scheme 1). The detailed synthetic procedures and spectroscopic characterization (Fig. S1-S10, ESI) are described in the ESI. $\dagger$ The polymers were purified and fractionated by sequential Soxhlet extraction using different solvents. The main fraction of PBDT4TBT was isolated from chloroform, while the main fraction of PBDT4TffBT was isolated by boiling the remaining residue in the thimble with $o$-dichlorobenzene as a consequence of its lower solubility. The molecular weights of the polymers were determined by high temperature gel permeation chromatography (GPC) at $140{ }^{\circ} \mathrm{C}$ in $o$-dichlorobenzene. The number-average molecular weights $\left(M_{\mathrm{n}}\right)$ and polydispersity index (PDI) were, respectively, $40.1 \mathrm{~kg} \mathrm{~mol}^{-1}$ and 2.79 , for PBDT4TBT and $24.2 \mathrm{~kg} \mathrm{~mol}^{-1}$ and 2.01 for PBDT4TffBT. The lower molecular weight of PBDT4TffBT is a consequence of its reduced solubility (vide infra). This precludes the further elongation of the polymer chains during the polymerization reaction. Polymer molecular weight is one of the parameters that can influence the active layer morphology and the device performance. Often, higher molecular weights give higher PCEs, provided that the polymer can still be processed. ${ }^{31,32}$ For that reason, we compare in this study the highest molecular weight fractions we could obtain for the synthesized polymers.

\section{Thermal, optical and redox properties}

The thermal properties of the new polymers were characterized by thermogravimetric analysis (TGA) (Fig. S11, ESI $\dagger$ ) and differential scanning calorimetry (DSC) measurements (Fig. S12, ESI $\dagger$ ). In TGA no substantial weight loss was detected up to $400{ }^{\circ} \mathrm{C}$ and both polymers possess a high thermal stability. In DSC (Fig. S12, $\mathrm{ESI} \dagger$ ) the polymers exhibit a glass transition at about $43-44{ }^{\circ} \mathrm{C}$ within the evaluated temperature range $\left(-80\right.$ to $\left.350{ }^{\circ} \mathrm{C}\right)$.

The ultraviolet-visible-near infrared absorption and fluorescence spectra of the polymers in $o$-dichlorobenzene solution and as spin-coated thin films on glass are shown in Fig. 1 and summarized in Table 1. In solution, the polymers exhibit a structureless low-energy band ( 500-700 nm) together with a weaker band at higher energy. The absorption maximum of PBDT4TffBT is bathochromically shifted compared to that of PBDT4TBT. The bathochromic shift can originate from the planarization of the polymer backbone, promoted by the noncovalent intrachain $\mathrm{F} \cdots \mathrm{S}$ and/or $\mathrm{F} \cdots \mathrm{H}$ interactions or from the enhanced charge-transfer character of the excitation. Additionally, a distinct shoulder at lower energies suggests partial aggregation of PBDT4TfBBT in solution at room temperature. In thin films, the closer proximity of the polymer chains induces increased interchain stacking between the $\pi$-conjugated backbones, explaining the observed red shift of the spectra. This spectral shift is more pronounced in the case of the nonfluorinated PBDT4TBT, which seems less aggregated in solution. The low-energy shoulder observed in the solution spectrum of PBDT4TfBT evolves towards a better resolved and more
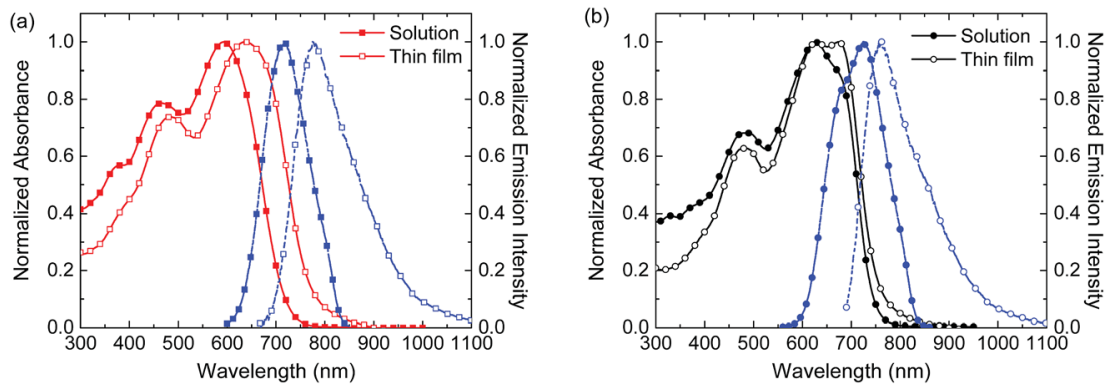

Fig. 1 Normalized absorption (solid lines) and fluorescence (dashed lines) spectra in o-dichlorobenzene solution (solid markers) and thin films (open markers) for (a) PBDT4TBT and (b) PBDT4TffBT. 
Table 1 Optoelectronic properties

\begin{tabular}{|c|c|c|c|c|c|c|c|c|}
\hline Polymer & $\lambda_{\max }^{\mathrm{abs}, \mathrm{sol}}(\mathrm{nm})$ & $\lambda_{\max }^{\mathrm{abs}, \mathrm{film}}(\mathrm{nm})$ & $\lambda_{\max }^{\mathrm{em}, \mathrm{sol}}(\mathrm{nm})$ & $\lambda_{\max }^{\mathrm{em}, \mathrm{film}}(\mathrm{nm})$ & $E_{\mathrm{g}}^{\mathrm{opt}, \mathrm{film} a}(\mathrm{eV})$ & $E_{\mathrm{g}}^{\mathrm{CV} b}(\mathrm{eV})$ & $E_{\text {номо }}^{c}(\mathrm{eV})$ & $E_{\text {LUMO }}^{d}(\mathrm{eV})$ \\
\hline PBDT4TBT & 593 & 637 & 718 & 775 & 1.62 & 1.78 & -5.28 & -3.50 \\
\hline PBDT4TffBT & 625 & 673 & 726 & 762 & 1.65 & 1.91 & -5.42 & -3.51 \\
\hline
\end{tabular}

${ }^{a}$ Estimated from the onset of the lower energy band of the absorption spectrum. ${ }^{b}$ Estimated as the difference between the onsets of the oxidation and reduction waves in the cyclic voltammogram. ${ }^{c} E_{\mathrm{HOMO}}=-\left(5.23+E_{\mathrm{onset}}^{\mathrm{ox}}\right) \cdot{ }^{d} E_{\mathrm{LUMO}}=-\left(5.23+E_{\mathrm{onset}}^{\mathrm{red}}\right)$.

intense vibronic peak due to the further planarization of the polymer aggregates. The polymers possess similar optical band gaps with values of $1.62 \mathrm{eV}$ for PBDT4TBT and $1.65 \mathrm{eV}$ for PBDT4TfBT, as estimated from the onset of absorption in the films.

The fluorescence spectra of the solutions of PBDT4TBT and PBDT4TffBT exhibit a single band (Fig. 1). The emission spectra of the corresponding films are broader and appear red-shifted. The (apparent) Stokes shift is smaller for PBDT4TffBT than for PBDT4TBT, both in solution (101 nm vs. $125 \mathrm{~nm})$ and in the solid state (89 nm vs. $138 \mathrm{~nm}$ ), suggesting a more ordered molecular structure for the fluorinated derivative.

The effect of temperature on conformation and aggregation was evaluated by recording the absorption spectra of $o$-dichlorobenzene solutions of PBDT4TBT and PBDT4TfBBT. Fig. 2 reveals a markedly dissimilar temperature-dependent behavior. The absorption of PBDT4TBT (Fig. 2a) shows a gradual hypsochromic shift accompanied by a decrease of intensity with increasing temperature. The shift can be interpreted as a signature of a higher conformational flexibility of the polymer chains at higher temperature, while the intensity decrease is at least in part caused by expansion of the solvent. In contrast, for PBDT4TffBT, the shoulder assigned to the interchain $\pi$-aggregates gradually disappears at higher temperatures and there is a small, but distinct, increase of the absorption of molecularly dissolved chains at $\sim 540 \mathrm{~nm}$ (Fig. 2b). These changes are a consequence of a temperature-induced dissolution of polymer chains from aggregates at $20{ }^{\circ} \mathrm{C}$ towards molecularly dissolved non-planar chains at $100{ }^{\circ} \mathrm{C}$. There is, however, no distinct isosbestic point because the spectral changes are a consequence of two temperature-dependent processes, i.e. aggregation and conformational flexibility. At $100{ }^{\circ} \mathrm{C}$ the absorption maxima of
PBDT4TBT (542 nm) and PBDT4TffBT (536 nm) are almost identical.

The redox potentials of the polymer films were determined using cyclic voltammetry (Fig. 3a). The voltammograms show two quasi-reversible reduction waves and one irreversible oxidation. The onsets of these redox waves were used to estimate the energies of the HOMO and LUMO levels (Table 1 and Fig. 3b). Both polymers have virtually the same LUMO energies but the HOMO level is lower for PBDT4TffBT $(-5.42 \mathrm{eV})$ than for PBDT4TBT $(-5.28 \mathrm{eV})$ as a consequence of the electronegative character of fluorine.

\section{Photovoltaic properties}

Solution processed bulk-heterojunction solar cells were fabricated by blending the polymers with $[6,6]$-phenyl- $\mathrm{C}_{71}$-butyric acid methyl ester ([70]PCBM) using a conventional device configuration consisting of a transparent indium tin oxide/ poly(3,4-ethylenedioxythiophene):poly(styrene sulfonate) (ITO/ PEDOT:PSS) front contact and a reflective LiF/Al back contact. The experimental details are provided in the Experimental section. The devices were optimized in terms of donor : acceptor ratio, processing temperature, type and amount of solvent additives, and post-annealing treatment. Fig. 4a shows the current density-voltage $(J-V)$ characteristics of the optimized devices under simulated air mass 1.5 (AM1.5) solar illumination and in the dark. The relevant photovoltaic parameters are listed in Table 2. PBDT4TfBT:[70]PCBM blends spin coated from $o$ dichlorobenzene provided higher short-circuit currents $\left(J_{\mathrm{SC}}\right)$ than the PBDT4TBT:[70]PCBM blends (11.58 vs. $9.40 \mathrm{~mA} \mathrm{~cm}{ }^{-2}$ ). Surprisingly, both polymers gave a comparable $V_{\text {OC }}$, even though the fluorinated polymer has a $0.14 \mathrm{eV}$ deeper HOMO level. The
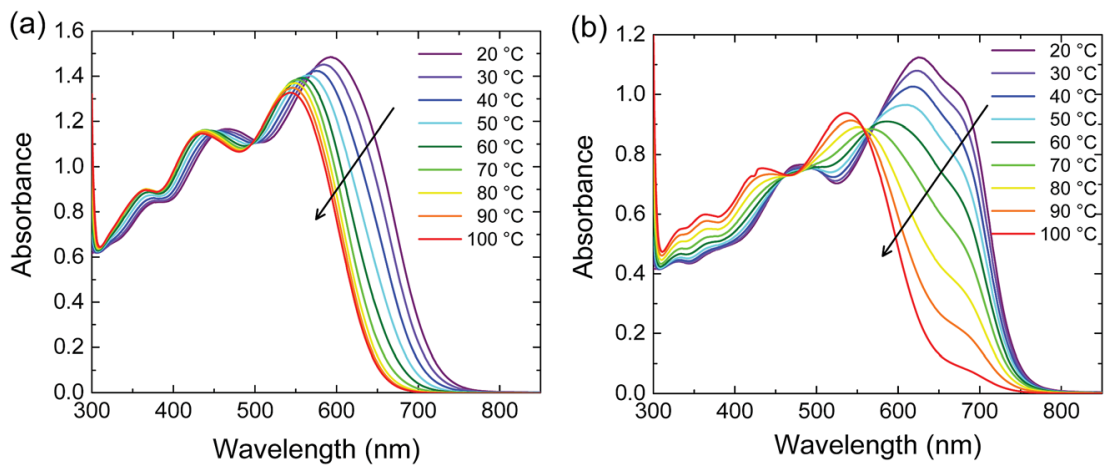

Fig. 2 Temperature dependent absorption of (a) PBDT4TBT and (b) PBDT4TffBT in o-dichlorobenzene solution. Arrows indicate the heating direction. 

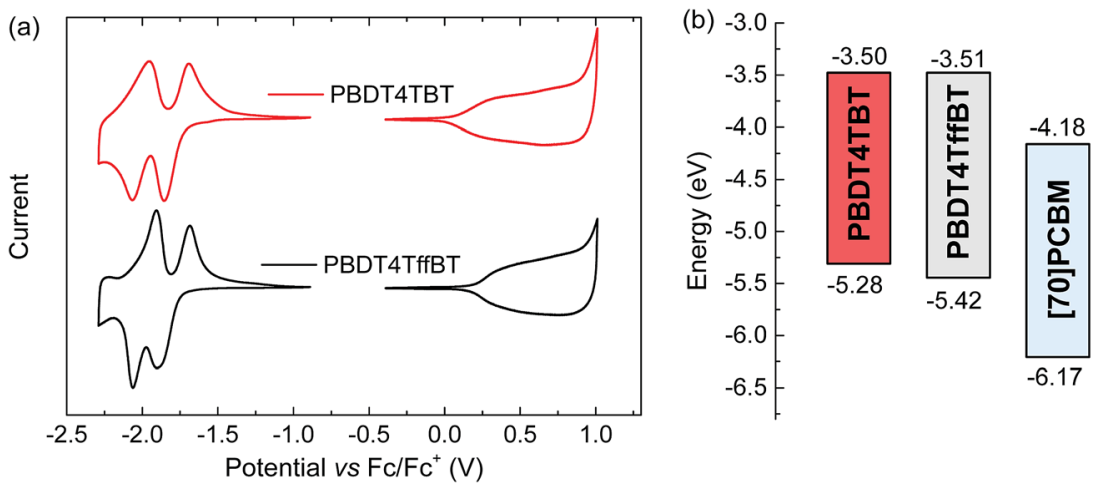

Fig. 3 (a) Cyclic voltammograms of thin polymer films on an ITO working electrode immersed in acetonitrile containing $0.1 \mathrm{M}$ tetrabutylammonium hexafluorophosphate as the supporting electrolyte. The scan rate was $100 \mathrm{mV} \mathrm{s}^{-1}, \mathrm{a} \mathrm{Ag} / \mathrm{AgCl}$ electrode was used as the reference electrode and a silver rod as the counter electrode; (b) HOMO and LUMO energy levels.
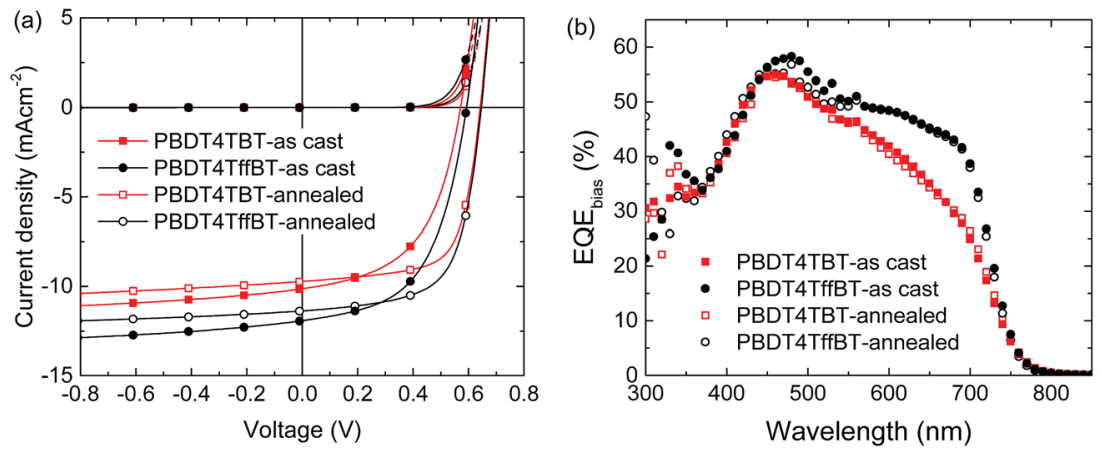

Fig. 4 (a) Current density-voltage characteristics of solar cells in the dark and under simulated AM1.5G illumination. (b) EQE of the optimized devices.

origin of this difference is studied and discussed in detail in the section "Charge recombination and charge transfer state" (vide infra). Hence, the difference in $J_{\mathrm{SC}}$ accounts for the higher PCE of PBDT4TfBT $(3.73 \%)$ compared to PBDT4TBT $(2.82 \%)$. The higher photocurrent suggests a more favorable intermolecular arrangement or more intimate mixed morphology at the donor/ acceptor interface for the fluorinated derivative. ${ }^{33}$

Thermal annealing resulted in a distinct improvement in the PCE. For PBDT4TBT the $V_{\mathrm{OC}}$ and FF continuously improve with annealing temperature, reaching a maximum at $200{ }^{\circ} \mathrm{C}$, while $J_{\mathrm{sC}}$ varies between 8.8 and $9.4 \mathrm{~mA} \mathrm{~cm}^{-2}$ in the same temperature range (Fig. 5a). The optimized thermally annealed $\left(200{ }^{\circ} \mathrm{C}\right)$ device (PCE $=4.06 \%$ ) outperforms the as-cast device (Table 2). For PBDT4TfBT, $V_{\mathrm{OC}}$ and FF also increase with temperature, but $J_{\mathrm{SC}}$ decreases continuously (Fig. 5b). The maximum PCE $=$ $4.44 \%$ is reached after annealing at $150{ }^{\circ} \mathrm{C}$ (Table 2). Concomitant with an enhanced $V_{\mathrm{OC}}$, the built-in potential of the solar cells increases after thermal annealing (Fig. S13, ESI $\dagger$ ). ${ }^{34} \mathrm{We}$ notice that the HOMO and LUMO energies of polymer films as determined with cyclic voltammetry are the same within the experimental error, before and after the thermal treatment. The result that the photovoltaic parameters change with temperature is a consequence of a change in morphology, which affects the energy levels, charge generation, transport and recombination. The fact that the HOMO and LUMO levels of the pure polymer films do not change after annealing while the $V_{\mathrm{OC}}$ shows a clear increase is consistent with our observation from X-ray diffraction that the blends with [70]PCBM show more

Table 2 Photovoltaic parameters

\begin{tabular}{|c|c|c|c|c|c|c|c|}
\hline Polymer & $T\left({ }^{\circ} \mathrm{C}\right)$ & $J_{\mathrm{SC}}\left(\mathrm{mA} \mathrm{cm}^{-2}\right)$ & $J_{\mathrm{SC}}^{\mathrm{SR} a}\left(\mathrm{~mA} \mathrm{~cm}^{-2}\right)$ & $V_{\mathrm{OC}}(\mathrm{V})$ & $\mathrm{FF}$ & PCE (\%) & $\operatorname{PCE}^{b}(\%)$ \\
\hline PBDT4TBT & $\mathrm{n} / \mathrm{a}$ & $10.10(10.00 \pm 0.07)$ & 9.40 & $0.57(0.57 \pm 0.00)$ & $0.52(0.50 \pm 0.02)$ & $3.04(2.87 \pm 0.12)$ & 2.82 \\
\hline PBDT4TBT & 200 & $9.72(9.65 \pm 0.08)$ & 9.35 & $0.64(0.64 \pm 0.00)$ & $0.68(0.67 \pm 0.01)$ & $4.23(4.18 \pm 0.04)$ & 4.06 \\
\hline PBDT4TffBT & 150 & $11.40(11.33 \pm 0.10)$ & 10.64 & $0.65(0.65 \pm 0.00)$ & $0.65(0.64 \pm 0.01)$ & $4.74(4.66 \pm 0.10)$ & 4.44 \\
\hline
\end{tabular}

${ }^{a}$ Calculated by integration of the EQE spectrum. ${ }^{b}$ Based on $J_{\mathrm{SC}}^{\mathrm{SR}}$. 


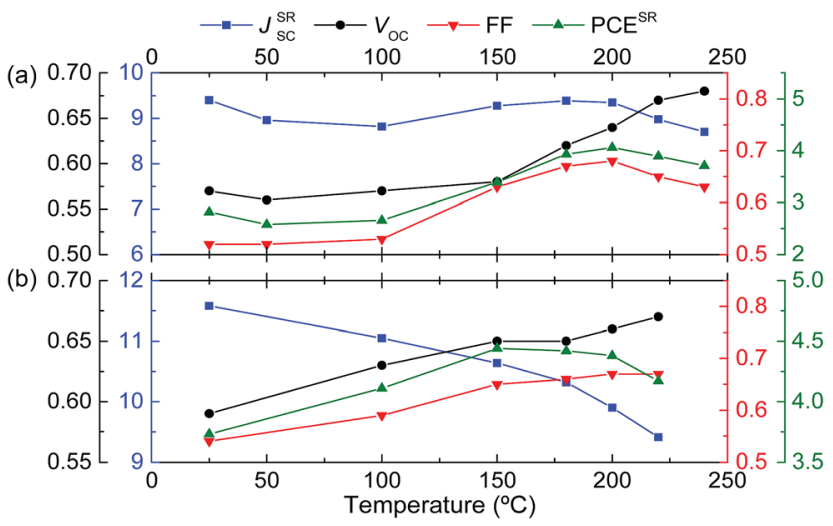

Fig. 5 Evolution of the photovoltaic parameters with the annealing temperature for (a) PBDT4TBT and (b) PBDT4TffBT.

pronounced changes, especially for PBDT4TBT, than the pure materials (vide infra). The external quantum efficiency (EQE) of the polymer blends reveals the contribution of both the donor and the acceptor to the photocurrent (Fig. 4b). The spectra are virtually identical below $\sim 500 \mathrm{~nm}$ and display a maximum EQE of $56 \%$ in the fullerene absorbing region (Fig. $4 \mathrm{~b}$ ). In the wavelength range where the polymers have their main absorption (500-780 nm), the EQE of PBDT4TffBT is higher than that of PBDT4TBT.

\section{Morphological characterization}

The morphology of the blends was investigated to determine the origin of the differences in the device performance and the changes observed upon annealing. The absorption and photoluminescence spectra of the pristine polymers and the blends with [70]PCBM recorded before and after thermal annealing are shown in Fig. 6. Pure PBDT4TBT and PBDT4TffBT films exhibit small hypochromic and hyperchromic effects, respectively, while the band shape remains the same. In the blends with [70] PCBM, the effect of thermal annealing is very small for PBDT4TffBT, but more distinct for PBDT4TBT where annealing causes an increased absorption between 600 and $700 \mathrm{~nm}$. In general, changes in absorption originate from changes in polymer planarization, aggregation and crystallization in combination with a possible change of the preferred order, but they can also be due to changes in the film thickness or refractive index. The overall changes are fairly small $(<10 \%)$, which introduces the risk of over-interpreting the observed differences compared to experimental uncertainties. The increased absorption of the PBDT4TBT:[70]PCBM films after annealing is, however, consistent with the increased crystallization of these blends as inferred from the X-ray diffraction (vide infra). The small loss in absorption of the pure PBDT4TBT film after annealing and the gain in absorption for PBDT4TffBT are possibly related to a change in the preferred order.

The fluorescence intensity of the pristine PBDT4TBT film decreases after annealing. We tentatively attribute this to the enhanced crystallinity after annealing (vide infra), which enhances the exciton diffusion rate, resulting in more trap quenching. For pristine PBDT4TffBT annealing does not really change the crystallinity (vide infra) and the very small increase can be due to the slightly higher absorption (Fig. 6b). The fluorescence in the blend films is significantly quenched compared to the pure polymers as a consequence of efficient exciton dissociation at the donor/acceptor interface (Fig. 6c and d). The residual emission of the polymers increased in intensity after annealing. This residual emission generally originates from excitons that are generated in larger pure polymer
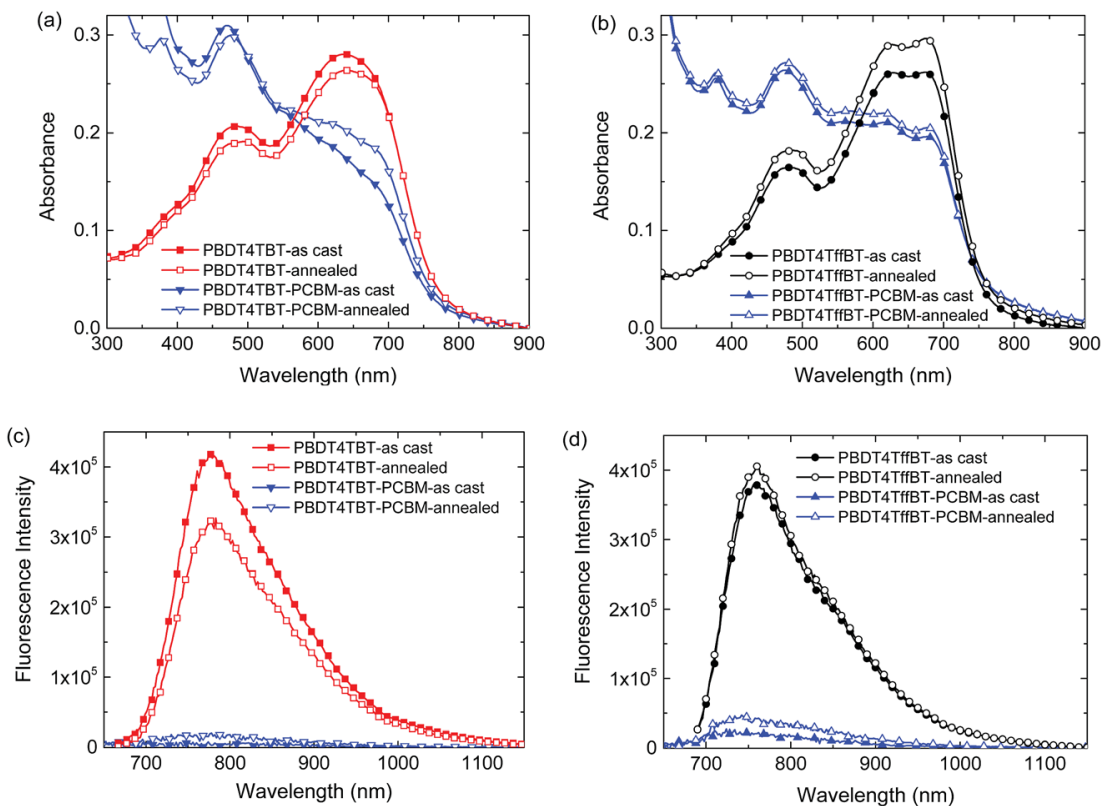

Fig. 6 Absorption ( $a$ and b) and fluorescence (c and d) spectra of the as-cast (closed symbols) and annealed (open symbols) pristine polymer films and blends with [70]PCBM for $(a-c)$ PBDT4TBT and $(b-d)$ PBDT4TffBT. 
domains and do not reach the donor/acceptor interface. The higher intensity after annealing thus indicates that these pure polymer domains have increased in number or size.

The morphology of the blends was investigated by atomic force microscopy (AFM), transmission electron microscopy (TEM) and two-dimensional grazing incidence wide angle X-ray scattering (2D GIWAXS). The AFM images of the as-cast blends (Fig. 7a and c) show a very smooth surface topology with a rootmean-square roughness $\left(R_{\mathrm{q}}\right)$ of $0.67 \mathrm{~nm}$ for the PBDT4TBT:[70] PCBM blends and $0.75 \mathrm{~nm}$ for the PBDT4TffBT:[70]PCBM blends. In both cases, a rougher surface was found after the thermal annealing $\left(R_{\mathrm{q}}=1.28\right.$ and $1.32 \mathrm{~nm}$, Fig. $7 \mathrm{~b}$ and $\left.\mathrm{d}\right)$. Consistent with the AFM results, the TEM images of the postannealed blends (Fig. $7 \mathrm{f}$ and h) revealed a slightly increased contrast, suggesting more pronounced phase separation, compared to those of the as-cast blends (Fig. 7e and g).

The 2D GIWAXS patterns of the pristine PBDT4TBT and PBDT4TffBT polymers and their blends with [70]PCBM before and after thermal annealing are shown in Fig. S14 (ESI $\dagger$ ). The corresponding line cut profiles for the out-of-plane and in-plane reflections are collected and shown in Fig. 8. The 2D-GIWAXS data confirm the main results inferred from optical absorption, fluorescence, $J-V$ and EQE characteristics, AFM and TEM. For the pure as-cast films, PBDT4TBT shows less intense reflections than PBDT4TffBT (Fig. 8a and b), implying that it is less ordered. Thermal annealing has virtually no effect on the pure PBDT4TffBT films, but for the less ordered PBDT4TBT the intensity of the reflections increases slightly and a weak second order (200) reflection appears in the out-of-plane direction. The fluorinated polymer (PBDT4TffBT) has an almost perfect edgeon orientation showing $(h 00)$ reflections up to the $4^{\text {th }}$ order $\left(q_{100}=0.302 \AA^{-1}, d_{100}=20.8 \AA\right)$ in the out-of-plane direction and a $\pi-\pi$ stacking reflection $\left(q_{001}=1.765 \AA^{-1}, d_{001}=3.56 \AA\right)$ in the in-plane direction. In contrast, the non-fluorinated polymer
(PBDT4TBT) has a less preferred orientation and shows a combination of edge-on and face-on arrangements with a slightly larger lamellar spacing $\left(q_{100}=0.280 \AA^{-1}, d_{100}=\right.$ $22.4 \AA)$ and $\pi-\pi$ stacking $\left(q_{001}=1.758 \AA^{-1}, d_{001}=3.58 \AA\right)$ in the out-of-plane direction.

In the blends with [70]PCBM the effects of thermal annealing are more pronounced, especially for the non-fluorinated polymer blend (PBDT4TBT:[70]PCBM); sharper and more reflections can be seen in both out-of-plane and in-plane directions for the lamellar spacing but also for the $\pi-\pi$ stacking reflection in the in-plane direction. In this case also the reflections associated with [70]PCBM at $q=0.68$ and $1.34 \AA^{-1}$ increase in intensity and decrease in width. Similar, but less pronounced changes occur for the PBDT4TffBT:[70]PCBM blend. Overall the increased crystallinity after thermal annealing matches with the improved fill factors (FF, Table 2) because of better charge transport and with the more intense residual fluorescence because of the increased domain size, which is also reflected in a small loss in $J_{\text {SC }}$ (Table 2).

Summarizing, the absorption, fluorescence, AFM, TEM, and 2D-GIWAXS results are consistent with an increased aggregation of polymer chains after annealing in their blends with [70] PCBM. As a consequence exciton dissociation is decreased upon thermal annealing, resulting in a gradual loss of $J_{\mathrm{sc}}$. For PBDT4TBT this loss is partly compensated by an increased absorption due to aggregation (Fig. 6a). PBDT4TffBT cells do not profit from this effect, because the as-cast films are already aggregated (Fig. 6b).

\section{Charge recombination and the charge transfer state}

Charge carrier recombination was investigated by recording $J_{\mathrm{SC}}$ $v s$. photon flux. ${ }^{35,36} J_{\mathrm{SC}}$ follows a power law dependence on photon flux $(\Phi)$ expressed as follows:
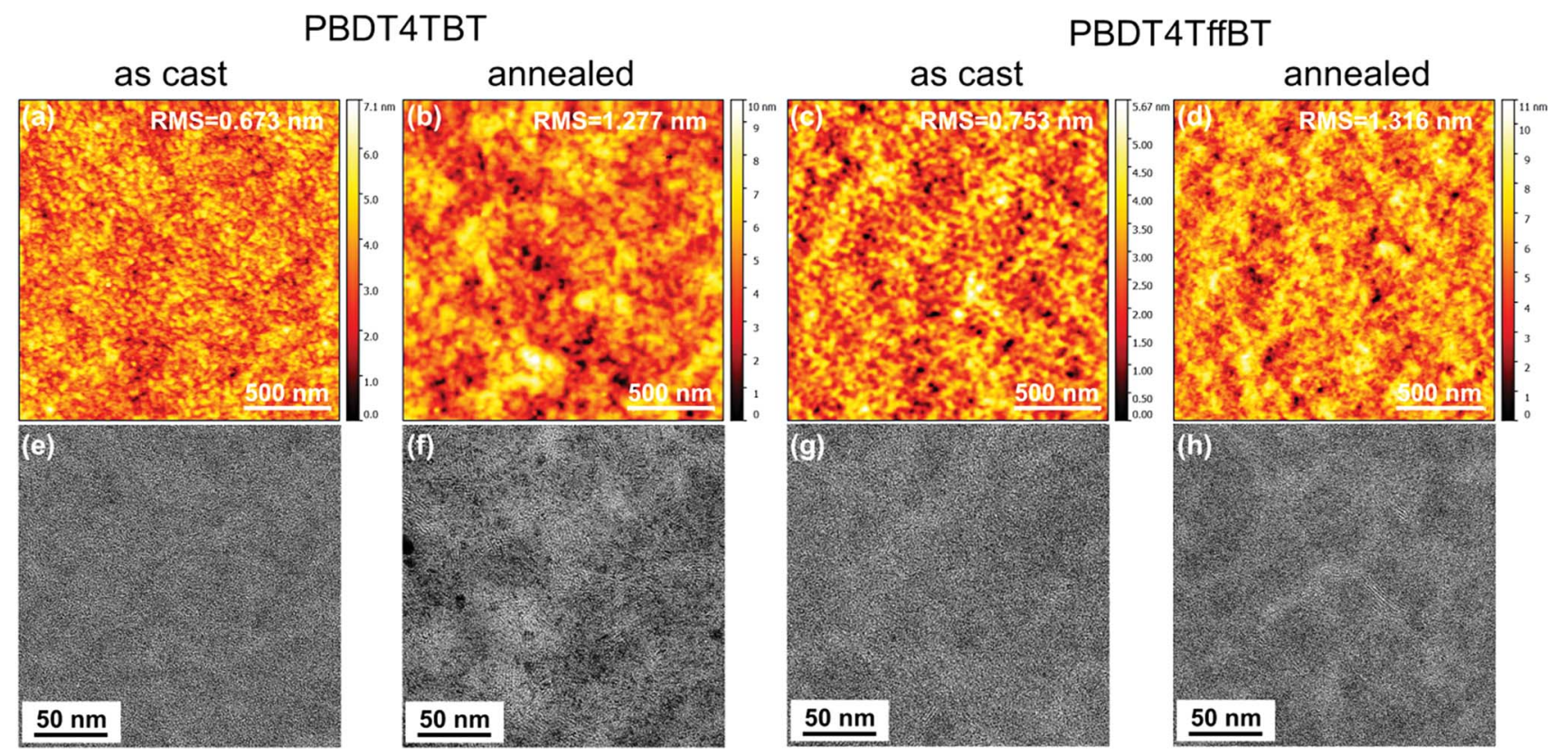

Fig. 7 Tapping-mode AFM height ( $(a-d)$ and TEM (e-h) images of the PBDT4TBT:[70]PCBM and PBDT4TffBT:[70]PCBM blends. 

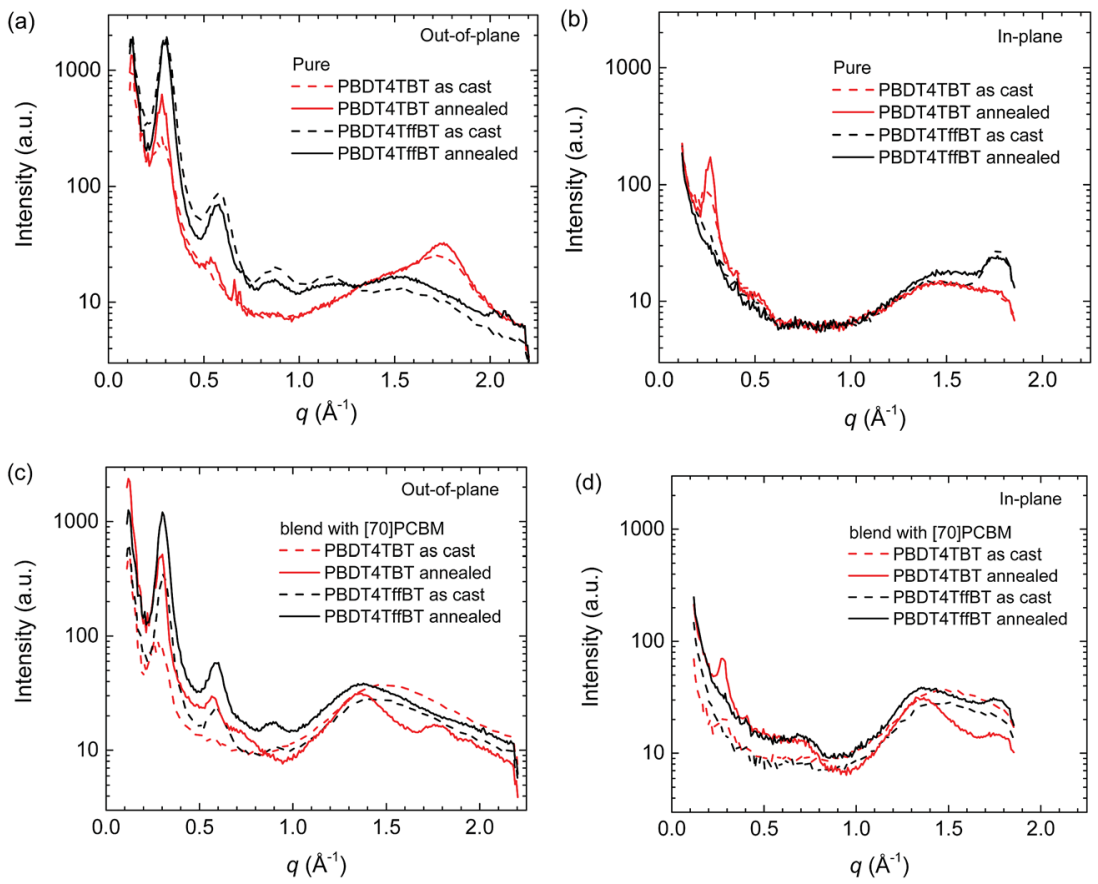

Fig. 8 Out-of-plane ( $a$ and $c$ ) and in-plane ( $b$ and $d$ ) line cut profiles from 2D-GIWAXS for pristine PBDT4TBT and PBDT4TffBT polymers and their blends with [70]PCBM before and after thermal annealing.

$$
J_{\mathrm{SC}} \propto \Phi^{\alpha}
$$

where a deviation of the exponent $\alpha$ from unity is indicative of bimolecular recombination. In a plot of $\log \left(J_{\mathrm{SC}}\right) v s . \log (\Phi)$ the differences in slopes are very small (see the inset in Fig. 9a) and any dissimilarity in the bimolecular recombination cannot be discerned. By plotting the first derivative of $\log \left(U_{\mathrm{sC}}\right)$ with respect to $\log (\Phi)$ (which corresponds to $\alpha$ ) as a function of $\log (\Phi)$ the value of $\alpha$ can be seen as a function of $\log (\Phi)$ (Fig. 9a). In general the $\alpha$ values for devices based on PBDT4TBT and PBDT4TffBT, before and after annealing, are close to unity and consequently, most charges are efficiently extracted at short-circuit with a virtually negligible bimolecular recombination. However, a small deviation from unity can be clearly discerned, particularly at higher light intensities (Fig. 9a). This deviation is more pronounced for the as-cast devices than for the annealed ones, suggesting a reduction of the bimolecular recombination with the thermal annealing of the blends. The average $\alpha$ values close to unity suggest that geminate recombination is most likely the dominant process. ${ }^{37,38}$ Another way to estimate losses due to bimolecular recombination is by comparing the EQE recorded without and with 1 sun equivalent bias light. In such a case the bimolecular recombination loss efficiency, $\eta_{\mathrm{BR}}$, can be approximated using the following expression: ${ }^{39}$

$$
\eta_{\mathrm{BR}}=1-\mathrm{EQE}_{\text {bias }} / \mathrm{EQE}_{\text {nobias }}
$$

In concordance with the light intensity dependence studies, low averaged $\eta_{\mathrm{BR}}$ values were found (Fig. 9b). The bimolecular recombination was reduced upon thermal annealing for both polymer/fullerene blends from $4 \%$ to $2 \%$ for PBDT4TBT and
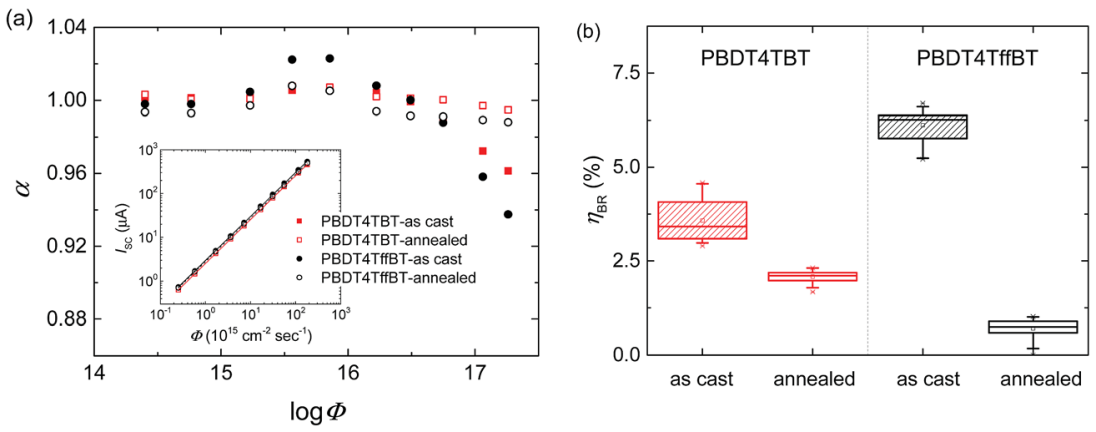

Fig. 9 (a) First derivative of $\log \left(\mathrm{J}_{\mathrm{SC}}\right)$ with respect to $\log (\Phi)$ as a function $\log (\Phi)$. Inset: double logarithmic plot of the short circuit current as a function of $\Phi$ for $530 \mathrm{~nm}$ photons. Lines correspond to the fits to a power law (eqn (1)). (b) Averaged bimolecular recombination loss efficiency estimated from EQEs using eqn (2), and $530 \mathrm{~nm}$ bias light. 


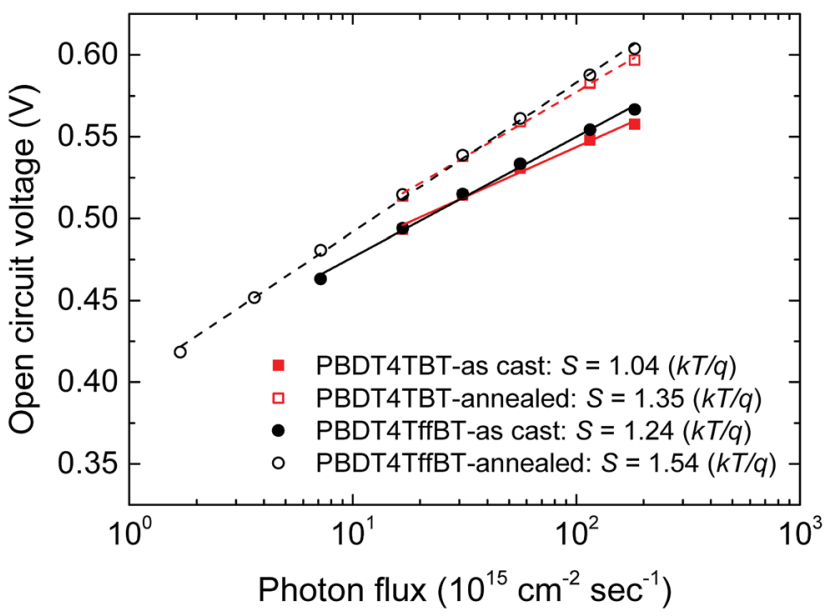

Fig. 10 Semi-logarithmic plot of the open circuit voltage as a function of the incident light intensity. Lines correspond to the fits to a linear function. The slope in the legend is in units of $k T / q$.

from $6 \%$ to $1 \%$ for PBDT4TffBT. Such a decrease in the bimolecular recombination explains the improved $V_{\mathrm{OC}}$ and $\mathrm{FF}$ of the annealed devices (Table 2). ${ }^{\mathbf{4 0 , 4 1}}$

At open-circuit all charges recombine. To gain insight into the prevailing recombination mechanism at open circuit, the change in $V_{\mathrm{OC}}$ with light intensity was investigated. The slope of $V_{\mathrm{OC}} v s$. light intensity in a semi-logarithmic plot gives the light ideality factor $\left(n_{1}\right)$ as a multiple of thermal energy $(k T / q)$ (Fig. 10). For both polymers the $V_{\mathrm{OC}}$ and $n_{1}$ increase upon thermal annealing. Generally, $n_{1}=1$ is associated with pure bimolecular recombination, while $n_{1}=2$ is characteristic of trap-assisted recombination in the bulk. ${ }^{42-44}$ We note, however, that trap-assisted surface recombination can also give rise to a low $n_{1}$ value. ${ }^{45}$ From the experiments shown in Fig. 9 we know that thermal annealing reduces bimolecular recombination, which results in an increase of $V_{\mathrm{OC}}$. The simultaneous increase of $n_{1}$ suggests that trap-assisted recombination becomes more dominant after annealing.

Dark ideality factors were calculated from the exponential region of the dark $J-V$ curves (Fig. S15, ESI $\dagger$ ) by using the expression $\eta_{\mathrm{d}}=[(k T / q)(\mathrm{dln} J / \mathrm{d} V)]^{-1}$. The dark ideality factors were larger than unity and moderately higher than the light ideality factors. We find good correspondence between both factors for the annealed devices. ${ }^{44-47}$

To understand the change in $V_{\mathrm{OC}}$ after annealing, we also investigated the energy of the charge transfer state $\left(E_{\mathrm{CT}}\right)$. It is experimentally well-established that $V_{\mathrm{OC}}$ and $E_{\mathrm{CT}}$ are linearly related. Hence variations in $V_{\mathrm{OC}}$ can be better described by correlation with $E_{\mathrm{CT}}$ than with the difference between the HOMO of the donor and the LUMO of the acceptor., ${ }^{5,12,48}$ Different methods and techniques have been employed to estimate $E_{\mathrm{CT}}{ }^{49-52}$ Here we employ sensitive EQE and electroluminescence (EL) measurements to investigate the sub-gap region (Fig. 11).

In the EQE measurements we see a considerable contribution of sub bandgap $(<1.6 \mathrm{eV})$ states. ${ }^{53}$ As can be seen in Fig. 11, the distribution of sub bandgap states is wider for PBDT4TffBT than for PBDT4TBT and increases with thermal annealing. Based on Marcus theory, ${ }^{54}$ the band shape of the EQE and EL originating from the CT state can be described using the following expressions: $:^{11,15}$

$$
\begin{gathered}
\mathrm{EQE}_{\mathrm{PV}}(E) \propto \frac{1}{E} \frac{1}{\sqrt{4 \pi \lambda k T}} \exp \left(-\frac{\left(E_{\mathrm{CT}}+\lambda-E\right)^{2}}{4 \lambda k T}\right) \\
\operatorname{EL}(E) \propto E \frac{1}{\sqrt{4 \pi \lambda k T}} \exp \left(-\frac{\left(E_{\mathrm{CT}}-\lambda-E\right)^{2}}{4 \lambda k T}\right)
\end{gathered}
$$
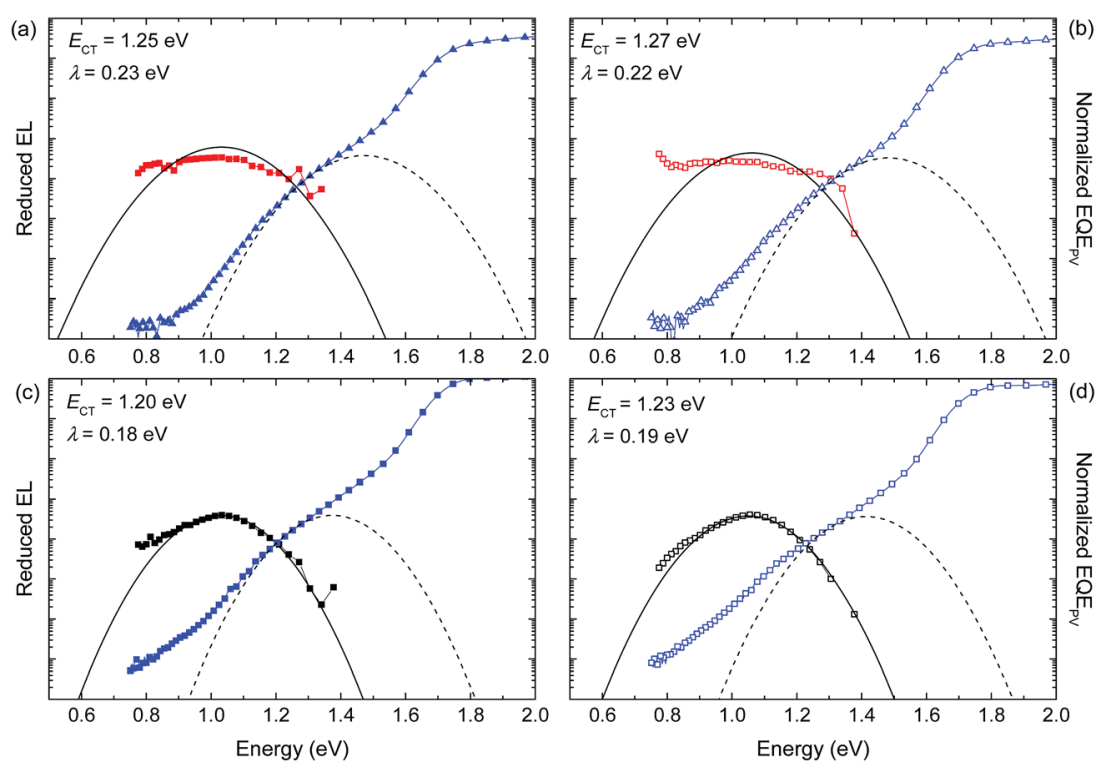

Fig. 11 Normalized EQE (blue symbols) and EL (red and black symbols) spectra for the as-cast and annealed devices of (a and b) PBDT4TBT:[70] PCBM and ( $c$ and d) PBDT4TffBT:[70]PCBM. Dashed and solid lines correspond to the fits based on eqn (3) and (4) to the data. 
Table 3 Charge transfer state parameters

\begin{tabular}{llllllc}
\hline Polymer & Treatment & $E_{\mathrm{CT}}(\mathrm{eV})$ & $\lambda(\mathrm{eV})$ & $q V_{\mathrm{OC}}(\mathrm{eV})$ & $E_{\mathrm{CT}}-q V_{\mathrm{OC}}(\mathrm{eV})$ & $E_{\mathrm{g}}-E_{\mathrm{CT}}(\mathrm{eV})$ \\
\hline PBDT4TBT & As cast & 1.25 & 0.23 & 0.57 & 0.68 & 0.37 \\
PBDT4TBT & Annealed & 1.27 & 0.22 & 0.64 & 0.63 & 0.35 \\
PBDT4TffBT & As cast & 1.20 & 0.18 & 0.59 & 0.61 & 0.45 \\
PBDT4TffBT & Annealed & 1.23 & 0.19 & 0.65 & 0.58
\end{tabular}

where $E$ is the photon energy and $\lambda$ the reorganization energy. Fig. 11 shows that the sub bandgap EQEs cannot be adequately fitted to eqn (3) when using a single combination of $E_{\mathrm{CT}}$ and $\lambda$. This suggests a distribution of CT states as has been observed for several donor/acceptor systems..$^{53,55-57}$ The increased contribution of low-energy photons to the photocurrent after annealing may indicate an increase of sub bandgap states. While these states could play a role in trap-assisted recombination, the fact that they show up in the EQE implies that charges created at these low photon energies can be collected and escape recombination.

Apart from EQE, EL allows to determine $E_{\mathrm{CT}}$ and $\lambda$ in an independent experiment. The EL spectra observed for the ascast and thermally annealed PBDT4TffBT:[70]PCBM films (Fig. 11c and d) can be fitted to eqn (4), providing estimates for $E_{\mathrm{CT}}$ and $\lambda$ (Table 3 ). The same $E_{\mathrm{CT}}$ and $\lambda$ parameters should fit the EQE using eqn (3). The fits (dashed lines in Fig. 11c and d) show a reasonable correspondence with the experimental EQE, but also emphasize that additional low energy $(<1.1 \mathrm{eV})$ states are present. For PBDT4TBT:[70]PCBM films, the situation is less clear and there is considerable uncertainty in the fitting. By simultaneously fitting the EQE and EL spectra we obtained only a fair agreement of the fits with the experimental data (Fig. 11a and b). Note that the absolute intensity of the EL of PBDT4TBT:[70]PCBM films was much less than that of PBDT4TffBT:[70]PCBM (Fig. S16, ESI $\dagger$ ), such that the dark count rate raises the wings of the normalized spectrum.

The fluorinated polymer has lower $E_{\mathrm{CT}}$ and $\lambda$ than the nonfluorinated analogue (Table 3 and Fig. 11). The lower $E_{\mathrm{CT}}$ for PBDT4TffBT is surprising because the HOMO energy of this polymer, determined from the oxidation potential, is lower than that of PBDT4TBT. The result can be rationalized by the fact that the fluorinated polymer is more ordered as can be inferred from the absorption spectra of the blends (Fig. 6a and b). Consistent with this explanation, the reorganization energy is also lower for the more ordered, fluorinated polymer. For both polymers $E_{\mathrm{CT}}$ increases slightly after thermal annealing whereas $\lambda$ remains virtually constant. Hence the CT states are affected by thermal annealing, but the increase in $E_{\mathrm{CT}}$ is less than the increase in $V_{\mathrm{OC}}$. As a consequence the $E_{\mathrm{CT}}-q V_{\mathrm{OC}}$ energy difference is reduced (Table 3 ), which indicates less nonradiative recombination. The absolute $E_{\mathrm{CT}}-q V_{\mathrm{OC}}$ values of $\sim 0.6 \mathrm{eV}$ obtained after annealing are consistent with the experimental values for many organic solar cells. ${ }^{15}$ Hence, the additional low energy $(<1.1 \mathrm{eV})$ sub-gap states that can be seen in the EQE spectra (Fig. 11) of these polymers, seem not to affect the $V_{\mathrm{OC}}$ considerably.

\section{Conclusions}

Two alternating BDT-4TBT copolymers have been synthesized that differ in the fluorine substitution on the BT unit. In bulk heterojunction solar cells, the fluorinated polymer exhibits a higher PCE. The performance of the as-cast devices was increased after thermal annealing at high temperatures (150$200{ }^{\circ} \mathrm{C}$ ), by a distinct increase in $V_{\mathrm{OC}}$ and $\mathrm{FF}$, but a concomitant loss in $J_{\mathrm{SC}}$ as a consequence of a more phase-separated blend morphology. After thermal annealing the dominant nongeminate charge recombination mechanism shifted from bimolecular or surface recombination to more trap-assisted recombination in the bulk. An analysis of the CT and reorganization energies revealed that a distribution of CT states exists. Surprisingly, the blends of the fluorinated polymer with [70] PCBM exhibited a lower CT state energy, despite its deeper HOMO level. The result can be rationalized by the fact that the fluorinated polymer is more ordered. Overall the $E_{\mathrm{CT}}-q V_{\mathrm{OC}}$ energy difference is reduced after annealing.

Although most results can be rationalized qualitatively, the data demonstrate that even a small structural modification, such as fluorination, can change the properties of these materials in a complex way where a subtle balance of electronic, conformational, and morphological changes determines the photovoltaic performance in a direction that is difficult to predict accurately. Solving this missing link remains a challenge for further progress of organic photovoltaics.

\section{Experimental}

Reagents used as starting materials and commercial solvents were used as received without further purification. Unless stated otherwise, all reactions were performed under an argon atmosphere. ${ }^{1} \mathrm{H}$ NMR, ${ }^{13} \mathrm{C}$ NMR and ${ }^{19} \mathrm{~F}$ NMR spectra were recorded on a Bruker spectrometer having frequencies of 400 $\mathrm{MHz}$ for proton nuclei, $100 \mathrm{MHz}$ for carbon nuclei and 376.3 $\mathrm{MHz}$ for fluorine nuclei. Chemical shifts are given in ppm and were referred to the residual peak from the deuterated solvent. MALDI-TOF mass spectroscopy was performed on a Bruker Autoflex Speed spectrometer. Molecular weights and polydispersity index (PDI) were determined by gel permeation chromatography at $140{ }^{\circ} \mathrm{C}$ on a PL-GPC 120 system using a PLGEL $10 \mu \mathrm{m}$ MIXED-C column and $o$-dichlorobenzene as the eluent against polystyrene standards. The samples were stirred in $o$-dichlorobenzene at $140{ }^{\circ} \mathrm{C}$ for one hour before injection.

Thermogravimetric analysis was carried out on a TA Instruments TGA Q500 instrument at a heating rate of $10{ }^{\circ} \mathrm{C} \mathrm{min}{ }^{-1}$ 
under nitrogen. Differential scanning calorimetry measurements were performed using a TA Instruments Q2000-1037 DSC with heating and cooling rates of $10{ }^{\circ} \mathrm{C} \mathrm{min}^{-1}$ under nitrogen. The second heating run was analyzed. UV-vis-NIR spectroscopy was conducted on a Perkin Elmer Lambda 1050 spectrophotometer. Emission and electroluminescence spectra were recorded on an Edinburgh Instruments FLSP920 doublemonochromator spectrophotometer equipped with a nitrogen cooled near-IR sensitive photomultiplier (Hamamatsu). The signals were corrected for the wavelength dependence sensitivity of the detection. Cyclic voltammetry was performed on thin films spin-coated on indium tin oxide (ITO) covered glass substrates under an inert atmosphere using an Autolab potentiostat with a scan speed of $0.1 \mathrm{~V} \mathrm{~s}^{-1}$ and $0.1 \mathrm{M}$ tetrabutylammonium hexafluorophosphate in acetonitrile as the electrolyte. Ferrocene was used as the internal reference, ITO as the working electrode, a silver rod as the counter-electrode, and a $\mathrm{Ag} / \mathrm{AgCl}$ electrode as the reference electrode.

For the photovoltaic device preparation pre-patterned ITO covered glass substrates (Naranjo Substrates), with an active area of 0.09 and $0.16 \mathrm{~cm}^{2}$, were cleaned by sonication in acetone, scrubbing and subsequent sonication with a sodium dodecyl sulfate solution, rinsing with demineralized water and finally, sonication in isopropanol for 15 minutes at each step. After 30 minutes of UV-ozone treatment, a thin layer $(\sim 40 \mathrm{~nm})$ of poly(3,4-ethylenedioxythiophene):poly(styrene sulfonate) (PEDOT:PSS) (Clevios P VP AI 4083) was spin-coated and annealed at $150{ }^{\circ} \mathrm{C}$ for 10 minutes. Then, the active layer consisting of a blend of the corresponding donor and [70]PCBM ( 1 : 1.5 by weight), which has been stirred at $90{ }^{\circ} \mathrm{C}$ overnight, was spin coated from the hot $o$-dichlorobenzene solution $(8 \mathrm{mg}$ $\mathrm{mL}^{-1}$ ). The layers were fully dried under vacuum immediately after spin coating for 10 minutes. Subsequently, the corresponding substrates were annealed in a hot plate for 5 minutes in a nitrogen filled glovebox. Finally, a $1 \mathrm{~nm}$ thick layer of $\mathrm{LiF}$ and a $100 \mathrm{~nm}$ thick layer of $\mathrm{Al}$ were thermally evaporated under high vacuum $\left(\sim 3 \times 10^{-7} \mathrm{mbar}\right)$. The active layer thicknesses ( $\sim 100 \mathrm{~nm})$ were measured with a Veeco Dektak 150 profilometer. $J-V$ characteristics were measured with a Keithley 2400 source meter under $\sim 100 \mathrm{~mW} \mathrm{~cm}{ }^{-2}$ white light illumination from a tungsten-halogen lamp filtered by a Schott GG385 UV filter and a Hoya LB120 daylight filter. Short-circuit currents under AM1.5G conditions were determined by integrating the spectral response with the solar spectrum. Spectral response measurements were conducted under 1 sun operating conditions by using a $530 \mathrm{~nm}$ high power LED (Thorlabs) for bias illumination. The device was kept in a nitrogen filled box behind a quartz window and irradiated with modulated monochromatic light, from a $50 \mathrm{~W}$ tungsten-halogen lamp (Osram 64610) and monochromator (Oriel, Cornerstone 130) with the use of a mechanical chopper. The response was recorded as a voltage from a preamplifier (SR570) using a lockin amplifier (SR830). A calibrated silicon cell was used as a reference. For the high sensitivity EQE measurements the devices were irradiated with modulated monochromatic light, from a $250 \mathrm{~W}$ tungsten-halogen lamp (Osram 64655HLX) and monochromator (Oriel, Cornerstone 260). Besides, a calibrated
InGaAs cell was also used as a reference. For the EL measurements a forward bias of $2.75 \mathrm{~V}$ was applied to the devices kept in a nitrogen filled box behind a quartz window in the same spectrometer as that used for the photoluminescence experiments. Light intensity measurements were performed at $530 \mathrm{~nm}$ using a high power LED (Thorlabs).

Atomic force microscopy (AFM) measurements were performed on an extended Veeco MultiMode AFM connected to a Nanoscope III controller in tapping mode using PPP-NCH-50 probes (Nanosensors). Transmission electron microscopy (TEM) was performed on a Tecnai G2 Sphera transmission electron microscope (FEI) operated at $200 \mathrm{kV}$.

The two-dimensional (2D) GIWAXS experiments were carried out on a GANESHA 300XL+ system from JJ X-ray in the X-ray lab at the DSM Materials Sciences Center (DMSC). The instrument is equipped with a Pilatus $300 \mathrm{~K}$ detector, with a pixel size of 172 $\mu \mathrm{m} \times 172 \mu \mathrm{m}$. The X-ray source is a Genix 3D Microfocus Sealed Tube X-ray Cu-source with an integrated monochromator (multilayer optic "3D version" optimized for SAXS) $(30 \mathrm{~W})$. The wavelength used is $\lambda=1.5408 \AA$. The detector moves in a vacuum chamber with the sample-to-detector distance varied between 0.115 and $1.47 \mathrm{~m}$ depending on the configuration used, as calibrated using silver behenate $\left(d_{001}=58.380 \AA\right)$. The minimized background scattering plus high-performance detector allows for a detectable $q$-range varying from $3 \times 10^{-3}$ to $3 \AA^{-1}$ ( 0.2 to $\left.210 \mathrm{~nm}\right)$. The sample was placed vertically on the goniometer and tilted to a glancing angle of $0.2^{\circ}$ with respect to the incoming beam. A small beam was used to obtain sharper features in the scattering pattern. The primary slit has a size of $0.3 \times 0.5 \mathrm{~mm}$, and the guard slit has a size of $0.1 \times 0.3 \mathrm{~mm}$. The accumulation time was $6 \mathrm{~h}$ for each measurement. The data plot was constructed and data reduction was conducted using GIXSGUI and SAXSGUI programs. ${ }^{58}$

\section{Conflicts of interest}

There are no conflicts to declare.

\section{Acknowledgements}

We thank Ms Fallon Colberts for the TEM images. M. M.-M. gratefully acknowledges the "Fundación Séneca, Agencia de Ciencia y Tecnología de la Región de Murcia” for a postdoctoral fellowship. The research has further received funding from the European Research Council under the European Union's Seventh Framework Programme (FP/2007-2013)/ERC Grant Agreement No. 339031 and from the Ministry of Education, Culture and Science (Gravity program 024.001.035).

\section{References}

1 National Renewable Energy Laboratory, N.R.E.L, http:// www.nrel.gov/ncpv/images/efficiency_chart.png.

2 R. A. J. Janssen and J. Nelson, Adv. Mater., 2013, 25, 18471858. 
3 T. Linderl, T. Zechel, M. Brendel, D. M. González, P. MüllerBuschbaum, J. Pflaum and W. Brütting, Adv. Energy Mater., 2017, 7, 1700237.

4 K. Kawashima, Y. Tamai, H. Ohkita, I. Osaka and K. Takimiya, Nat. Commun., 2015, 6, 10085.

5 K. Vandewal, A. Gadisa, W. D. Oosterbaan, S. Bertho, F. Banishoeib, I. V. Severen, L. Lutsen, T. J. Cleij, D. Vanderzande and J. V. Manca, Adv. Funct. Mater., 2008, 18, 2064-2070.

6 D. Veldman, S. C. J. Meskers and R. A. J. Janssen, Adv. Funct. Mater., 2009, 19, 1939-1948.

7 W. Li, K. H. Hendriks, A. Furlan, M. M. Wienk and R. A. J. Janssen, J. Am. Chem. Soc., 2015, 137, 22312234.

8 B. P. Rand, D. P. Burk and S. R. Forrest, Phys. Rev. B: Condens. Matter Mater. Phys., 2007, 75, 115327.

9 T. M. Burke, S. Sweetnam, K. Vandewal and M. D. McGehee, Adv. Energy Mater., 2015, 5, 1500123.

10 S. Chen, S.-W. Tsang, T.-H. Lai, J. R. Reynolds and F. So, Adv. Mater., 2014, 26, 6125-6131.

11 K. Vandewal, K. Tvingstedt, A. Gadisa, O. Inganäs and J. V. Manca, Phys. Rev. B: Condens. Matter Mater. Phys., 2010, 81, 125204.

12 K. R. Graham, P. Erwin, D. Nordlund, K. Vandewal, R. Li, G. O. Ngongang Ndjawa, E. T. Hoke, A. Salleo, M. E. Thompson, M. D. McGehee and A. Amassian, Adv. Mater., 2013, 25, 6076-6082.

13 D. Fazzi, M. Barbatti and W. Thiel, J. Phys. Chem. Lett., 2017, 8, 4727-4734.

14 S. Kwon, H. Kang, J.-H. Lee, J. Lee, S. Hong, H. Kim and K. Lee, Adv. Energy Mater., 2017, 7, 1601496.

15 K. Vandewal, Annu. Rev. Phys. Chem., 2016, 67, 113-133.

16 K. Vandewal, S. Albrecht, E. T. Hoke, K. R. Graham, J. Widmer, J. D. Douglas, M. Schubert, W. R. Mateker, J. T. Bloking, G. F. Burkhard, A. Sellinger, J. M. J. Fréchet, A. Amassian, M. K. Riede, M. D. McGehee, D. Neher and A. Salleo, Nat. Mater., 2014, 13, 63-68.

17 S. D. Collins, N. A. Ran, M. C. Heiber and T.-Q. Nguyen, Adv. Energy Mater., 2017, 7, 1602242.

18 L. Dou, J. You, Z. Hong, Z. Xu, G. Li, R. A. Street and Y. Yang, Adv. Mater., 2013, 25, 6642-6671.

19 S. Xiao, Q. Zhang and W. You, Adv. Mater., 2017, 29, 1601391.

20 X.-P. Xu, Y. Li, M.-M. Luo and Q. Peng, Chin. Chem. Lett., 2016, 27, 1241-1249.

21 N. Leclerc, P. Chávez, O. Ibraikulov, T. Heiser and P. Lévêque, Polymers, 2016, 8, 11.

22 Q. Zhang, M. A. Kelly, N. Bauer and W. You, Acc. Chem. Res., 2017, 50, 2401-2409.

23 F. Meyer, Prog. Polym. Sci., 2015, 47, 70-91.

24 C. Duan, A. Furlan, J. J. van Franeker, R. E. M. Willems, M. M. Wienk and R. A. J. Janssen, Adv. Mater., 2015, 27, 4461-4468.

25 A. C. Stuart, J. R. Tumbleston, H. Zhou, W. Li, S. Liu, H. Ade and W. You, J. Am. Chem. Soc., 2013, 135, 1806-1815.

26 N. Wang, Z. Chen, W. Wei and Z. Jiang, J. Am. Chem. Soc., 2013, 135, 17060-17068.
27 I.-B. Kim, S.-Y. Jang, Y.-A. Kim, R. Kang, I.-S. Kim, D.-K. Ko and D.-Y. Kim, ACS Appl. Mater. Interfaces, 2017, 9, 2401124019.

28 H. Yao, L. Ye, H. Zhang, S. Li, S. Zhang and J. Hou, Chem. Rev., 2016, 116, 7397-7457.

29 Y. Wang and T. Michinobu, J. Mater. Chem. C, 2016, 4, 62006214.

30 H. Zhou, L. Yang, S. Xiao, S. Liu and W. You, Macromolecules, 2010, 43, 811-820.

31 A. Katsouras, N. Gasparini, C. Koulogiannis, M. Spanos, T. Ameri, C. J. Brabec, C. L. Chochos and A. Avgeropoulos, Macromol. Rapid Commun., 2015, 36, 1778-1797.

32 Z. B. Henson, K. Müllen and G. C. Bazan, Nat. Chem., 2012, 4, 699.

33 K. R. Graham, C. Cabanetos, J. P. Jahnke, M. N. Idso, A. El Labban, G. O. Ngongang Ndjawa, T. Heumueller, K. Vandewal, A. Salleo, B. F. Chmelka, A. Amassian, P. M. Beaujuge and M. D. McGehee, J. Am. Chem. Soc., 2014, 136, 9608-9618.

34 S. Solak, A. G. Ricciardulli, T. Lenz, N. I. Crăciun, P. W. M. Blom and G. A. H. Wetzelaer, Appl. Phys. Lett., 2017, 110, 163301.

35 C. M. Proctor, M. Kuik and T.-Q. Nguyen, Prog. Polym. Sci., 2013, 38, 1941-1960.

36 G. Lakhwani, A. Rao and R. H. Friend, Annu. Rev. Phys. Chem., 2014, 65, 557-581.

37 S. R. Cowan, A. Roy and A. J. Heeger, Phys. Rev. B: Condens. Matter Mater. Phys., 2010, 82, 245207.

38 I. Riedel, J. Parisi, V. Dyakonov, L. Lutsen, D. Vanderzande and J. C. Hummelen, Adv. Funct. Mater., 2004, 14, 38-44.

39 L. J. A. Koster, M. Kemerink, M. M. Wienk, K. Maturová and R. A. J. Janssen, Adv. Mater., 2011, 23, 1670-1674.

40 A. Maurano, R. Hamilton, C. G. Shuttle, A. M. Ballantyne, J. Nelson, B. O'Regan, W. Zhang, I. McCulloch, H. Azimi, M. Morana, C. J. Brabec and J. R. Durrant, Adv. Mater., 2010, 22, 4987-4992.

41 B. Qi and J. Wang, Phys. Chem. Chem. Phys., 2013, 15, 89728982.

42 M. Lenes, S. W. Shelton, A. B. Sieval, D. F. Kronholm, J. C. Hummelen and P. W. M. Blom, Adv. Funct. Mater., 2009, 19, 3002-3007.

43 M. M. Mandoc, F. B. Kooistra, J. C. Hummelen, B. d. Boer and P. W. M. Blom, Appl. Phys. Lett., 2007, 91, 263505.

44 S. R. Cowan, W. L. Leong, N. Banerji, G. Dennler and A. J. Heeger, Adv. Funct. Mater., 2011, 21, 3083-3092.

45 K. Tvingstedt and C. Deibel, Adv. Energy Mater., 2016, 6, 1502230.

46 G. A. H. Wetzelaer, M. Kuik, M. Lenes and P. W. M. Blom, Appl. Phys. Lett., 2011, 99, 153506.

47 T. Kirchartz, F. Deledalle, P. S. Tuladhar, J. R. Durrant and J. Nelson, J. Phys. Chem. Lett., 2013, 4, 2371-2376.

48 M. Gruber, J. Wagner, K. Klein, U. Hörmann, A. Opitz, M. Stutzmann and W. Brütting, Adv. Energy Mater., 2012, 2, 1100-1108.

49 Z. Guan, H.-W. Li, Y. Cheng, Q. Yang, M.-F. Lo, T.-W. Ng, S.-W. Tsang and C.-S. Lee, J. Phys. Chem. C, 2016, 120, 14059-14068. 
50 F. E. Osterloh, M. A. Holmes, L. Chang, A. J. Moulé and J. Zhao, J. Phys. Chem. C, 2013, 117, 26905-26913.

51 K. Tvingstedt, K. Vandewal, A. Gadisa, F. Zhang, J. Manca and O. Inganäs, J. Am. Chem. Soc., 2009, 131, 11819-11824.

52 J. Behrends, A. Sperlich, A. Schnegg, T. Biskup, C. Teutloff, K. Lips, V. Dyakonov and R. Bittl, Phys. Rev. B: Condens. Matter Mater. Phys., 2012, 85, 125206.

53 R. A. Street, A. Krakaris and S. R. Cowan, Adv. Funct. Mater., 2012, 22, 4608-4619.

54 R. A. Marcus, J. Phys. Chem., 1989, 93, 3078-3086.

55 A. N. Brigeman, M. A. Fusella, Y. Yan, G. E. Purdum, Y.-L. Loo, B. P. Rand and N. C. Giebink, Adv. Energy Mater., 2016, 6, 1601001.
56 V. Belova, P. Beyer, E. Meister, T. Linderl, M.-U. Halbich, M. Gerhard, S. Schmidt, T. Zechel, T. Meisel, A. V. Generalov, A. S. Anselmo, R. Scholz, O. Konovalov, A. Gerlach, M. Koch, A. Hinderhofer, A. Opitz, W. Brütting and F. Schreiber, J. Am. Chem. Soc., 2017, 139, 8474-8486.

57 G. O. N. Ndjawa, K. R. Graham, S. Mollinger, D. M. Wu, D. Hanifi, R. Prasanna, B. D. Rose, S. Dey, L. Yu, J.-L. Brédas, M. D. McGehee, A. Salleo and A. Amassian, Adv. Energy Mater., 2017, 7, 1601995.

58 Z. Jiang, J. Appl. Crystallogr., 2015, 48, 917-926. 